\title{
Sobre: Protocolo de extracción de ADN en lotes de 10 mosquitos para la identificación de Plasmodium spp. mediante qPCR
}

\section{Sr. Director:}

Hemos leído con interés el excelente articulo original publicado por el Teniente Veterinario D. A. Pérez Rico et al: «Protocolo de extracción de ADN en lotes de 10 mosquitos para la identificación de Plasmodium spp. mediante qPCR» publicado en el no 2, volumen 69 año 2013 de la revista Sanidad Militar. Consideramos de sumo interés la metodología propuesta en el artículo, especialmente a la hora de realizar las tareas de inteligencia sanitaria previas al despliegue de nuestra Fuerza en los nuevos Teatros de Operaciones (TO,s.) que se nos encomienden.

Dado que, precisamente, las misiones actuales de nuestras Fuerzas Armadas implican que dichos TO,s. pueden estar ubicados en cualquier parte del mundo, consideramos nuestro deber realizar una corrección, no con ánimo de crítica sino con la finalidad de aclarar una cuestión escasamente conocida pero de importancia creciente. Las especies de Plasmodium patógenas en el hombre son cinco. Plasmodium knowlesi, conocido como patógeno de malaria en simios desde hace casi un siglo ${ }^{1}$, ha sido reportado en un número creciente de casos desde la primera serie de 2004 en la isla de Borneo $^{2}$. Actualmente sabemos que en determinadas localizaciones del sudeste asiático (Borneo, Malasia peninsular, Tailandia y China) la incidencia de $P$. knowlesi puede alcanzar hasta un $40 \%$ de los casos $^{3}$.

La detección de esta especie es de especial interés en inteligencia sanitaria, dado que los trofozoitos, esquizontes y gametocitos de $P$. knowlesi son morfológicamente indistinguibles de los de $P$. malariae, llegando a tasas de error de hasta el $73 \%$ de los diagnósticos de $P$. malariae en Borneo (3). Mientras que la malaria por $P$. malariae se asocia generalmente a un curso clínico benigno con carga parasitaria baja, P. knowlesi parasita a los hematíes en todas las fases de su ciclo y tiene un ciclo corto con alta tasa de incremento de parasitemia $^{1}$, por lo que puede devenir en un curso clínico de gravedad e incluso fatal en horas. En la actualidad se asume que toda malaria morfológicamente identificada como $P$. malariae en el sudeste asiático debe ser diagnosticada de $P$. knowlesi y sometida a estrecha vigilancia clínica mientras que no se demuestre lo contrario ${ }^{3,4}$. Tarea que en Territorio Nacional se facilita con la disponibilidad de tests rápidos para $P$. knowlesi ${ }^{4} \mathrm{y}$, precisamente con el diagnóstico de confirmación por PCR-multiplex para las cinco especies de Plasmodium spp., disponible en el Centro Nacional de Microbiología de Majadahonda 5 .

No cabe, a priori, esperar variación en los resultados del, insistimos, excelente trabajo de Pérez Rico A et al para aumentar la eficiencia en el procesamiento de lotes de 10 mosquitos, en relación a la corrección propuesta. En cualquier caso, consideramos que es preceptiva, y que debe tenerse en cuenta la emergencia de este nuevo patógeno, tanto por médicos de unidad, internistas, preventivistas, microbiólogos como veterinarios, ante el aumento del turismo sanitario a zonas de selva y ante el potencial despliegue de nuestra Fuerza en zonas selváticas asiáticas en operaciones o en maniobras conjuntas, como realizan nuestros aliados de la OTAN 6 .

\section{BIBLIOGRAFÍA}

1. Knowles R, Das Gupta BM. A study of monkey-malaria and its experimental transmission to man. Ind Med Gaz 1932; 67:301-21.

2. Singh B, Kim Sung L, Matusop A, et al. A large focus of naturally acquired Plasmodium knowlesi infections in human beings. Lancet 2004; 363:1017-24.

3. Cox-Sing J, Davis T, Lee KS, Shamsul S, Matusop A, Ratnam S, Rahman H, Conway DJ, Singh B. Plasmodium knowlesi Malaria in Humans Is Widely Distributed and Potentially Life Threatening. Clin Infect Dis 2008; 46:165-71

4. Askling et al.: Management of imported malaria in Europe. Malaria Journal 2012 11:328.

5. Resolución de 22 de marzo de 2013, del Instituto de Salud Carlos III, por la que se establecen los precios públicos por la prestación de servicios y actividades del organism (BOE ${ }^{\circ} 82$ de 2013)

6. Roughton SA, Green AD. Plasmodium Knowlesi Malaria: Assessing the Risk to the British Armed Forces. J R Army Med Corps 2012; 158(4):318-21.

Francisco Javier Membrillo de Novales. Capitán Médico. Antonio Fe Marqués. Coronel Médico. Almudena Gámez Rodríguez. Médico Civil. Carmelo Perea Perea. Coronel Médico. Servicio de Medicina Interna, Hospital Central de la Defensa. Madrid.

\section{RÉPLICA DEL AUTOR}

Excmo. Sr Director,

Según indica el Director Ejecutivo de la Revista, se ha recibido una Carta al Director donde matiza algún aspecto del trabajo titulado «Protocolo de extracción de ADN en lotes de 10 mosquitos para la identificación de Plasmodium spp. mediante qPCR» (Sanid. mil. 2013; 69 (2): 77-81) del que soy coautor. En primer lugar nos alegra que el trabajo haya tenido repercusión y se haya valorado positivamente por los autores de la citada Carta al Director. Se trata de una pequeña aportación para que el rendimiento del trabajo, en casos de recogidas de numerosos mosquitos, pueda mejorarse sin perder precisión en el diagnóstico. Como demostración de que la técnica de extracción propuesta funciona correctamente se recurrió a realizar una PCR cuantitativa a tiempo real siguiendo las indicaciones de un trabajo publicado en 2005 (Mangold et al. 2005)and SYBR Green was used for detection in a LightCycler instrument. Patient specimens infected at 0.01 to $0.02 \%$ parasitemia densities were detected, and 


\section{CARTAS AL DIRECTOR}

analytical sensitivity was estimated to be 0.2 genome equivalent per reaction. Melting curve analysis based on nucleotide variations within the amplicons provided a basis for accurate differentiation of Plasmodium falciparum, P. vivax, P. ovale, and P. malariae. For assay validation, 358 patient blood samples from the National University Hospital in Singapore and Evanston Northwestern Healthcare in Illinois were analyzed. Of 76 blinded patient samples with a microscopic diagnosis of P. falciparum, P. vivax, or P. ovale infection, 74 (97.4\% donde no se mencionaba la reciente incidencia del Plasmodium knowlesi. De igual forma debe de funcionar con otras técnicas basadas en PCR a tiempo real donde se incorporen dianas de ADN correspondientes a otras especies de Plasmodium e incluso a otros organismos como bacterias y virus. Por supuesto que estamos totalmente de acuerdo en que hay que incorporar esta especie en cualquier metodología diagnóstica de malaria sobre todo en las áreas de difusión de la misma. Nuestra intención es hacer aportaciones que permitan una evaluación del riesgo de transmisión de la malaria del personal civil y militar desplegado en Zonas de Operaciones a nivel local. Habitualmente los datos que se manejan son de áreas enormes que incluso abarcan a todo un país, sin embargo se pueden hacer evaluaciones locales geográficamente y muestreando los posibles vectores durante las diferentes épocas del año, para tener una idea concreta del riesgo en el caso de que los desplazamientos del personal sean siempre próximos a la Base. Facilitar el trabajo de laboratorio mediante el análisis por lotes es importante en tareas preventivas donde las capturas de vectores son sistemáticas. El análisis posterior de las especies de Plasmodium presentes se podrá realizar siempre con las técnicas más adecuadas y validadas en su caso.

En definitiva, se agradece la aportación realizada al estudio publicado y sirve de estímulo para seguir trabajando en esta línea de prevención de enfermedades transmitidas por vectores.

Atentamente

Jose Luis Vega Pla

Teniente Coronel Veterinario

Director del Laboratorio de Investigación Aplicada Cría Caballar de las Fuerzas Armadas. Córdoba 